\title{
Towards realistic models of plate tectonic evolution
}

\author{
ELODIE KENDALL ${ }^{1}$, STEPHAN V. SOBOLEV ${ }^{2}$, SASCHA \\ BRUNE $^{2}$, ANNE GLERUM ${ }^{2}$ AND FREDERIC GEHRKE ${ }^{2}$ \\ ${ }^{1}$ GFZ German Research Centre for Geosciences, Geodynamic \\ Modelling, Germany \\ ${ }^{2}$ GFZ German Research Centre for Geosciences \\ Presenting Author: kendall@gfz-potsdam.de
}

The operation of plate tectonics on Earth is unique among the rocky planets in the Solar system. It has moulded our planet's surface and influenced the deep interior. Despite its significance, the inception of plate tectonics and its subsequent evolution are still heavily debated. Recent studies have suggested that since $3 \mathrm{Ga}$ the rise of the continents and accumulation of sediments at continental edges and in trenches has provided lubrication for the stabilization of subduction and therefore is a crucial factor in controlling plate tectonic evolution (Sobolev and Brown, 2019 Nature). As a first step to confronting this hypothesis, we present $2 \mathrm{D}$ visco-plastic global mantle convection models with $100 \mathrm{My}-$ old lithosphere, a composite rheology and realistic phase transitions using the geodynamic modelling code ASPECT. Through the use of adaptive mesh refinement, we are able to reach high resolution in localized features such as trenches or at the free surface. We first focus on the relationship between plastic weakening of the lithosphere due to plume impingement and subduction initiation for various plate thicknesses and strengths in the Early Earth. We then present models which may represent the start of plate tectonics as well as the "boring billion" - a period of reduced tectonic activity between $1.75 \mathrm{Ga}$ and $0.75 \mathrm{Ga}$, possibly caused by the shortfall of sediments in trenches. We show the sensitivity of the dynamics of plate tectonics to friction, which can be used as a proxy for sediment influx. Specifically, we take models which have or have not established plate-tectonic like behaviour and change the friction coefficient in the range from 0.01 (fully lubricated trenches) to 0.1 (not lubricated trenches). We find that as friction decreases due to the rise of continents and increasing supply of sediments in trenches global plate tectonics may start. As friction increases, which is a first-order representation of a reduction in sediment supply to trenches, it is harder to initiate new subduction zones and those that do exist are characterized by thicker plates and tend to die out. These simplified scenarios with high friction already fit well with the proposed tectonic behaviour during the boring billion. 